\title{
Delayed Cerebral Metastasis of Breast Cancer: Case Report and Molecular Review
}

\section{Mestástase cerebral tardia de cancêr de mama: Relato de caso e revisão molecular}

\author{
Leonardo Dessesards Olijnyk ${ }^{1}$ (1) Artur Nobrega Lima Morais $^{1}$ Rodolfo Figueiredo Carvalho ${ }^{1}$ \\ Adriana Abrão ${ }^{1}$ Krunal Patel ${ }^{3}$ Carlos Eduardo Silva ${ }^{1,2}$ \\ ${ }^{1}$ Skull Base Surgery Institute, Hospital Ernesto Dornelles, Porto \\ Alegre, RS, Brazil \\ 2 Human Anatomy Department, Universidade Federal de Ciências da \\ Saúde de Porto Alegre (UFCSPA), Porto Alegre, RS, Brazil \\ ${ }^{3}$ Toronto Western Hospital\& Krembil Neuroscience Institute, University \\ Health Network \& University of Toronto, Toronto, ON, Canada

\begin{abstract}
Address for correspondence Leonardo Dessesards Olijnyk, MD, Instituto de Cirurgia da Base de Crânio - ICBC, Hospital Ernesto Dornelles, Porto Alegre, Brazil (e-mail: leonardo.olijnyk@gmail.com).
\end{abstract} \\ Arq Bras Neurocir 2019;38:336-341.
}
Abstract
Keywords
- breast cancer
- neuro-oncology
- delayed metastasis
Resumo
Palavras-chave
- câncer de mama
- neuro-oncologia
- metástase tardia

Breast cancer (BC) is a prevalent disease, and its incidence of brain metastasis (BM) varies from 5 to $30 \%$ according to the literature. We present the case of a delayed isolated cerebral metastasis in a female patient following a period of 16 years after the diagnosis and first treatment. During this time, there was no other recurrence. We also review the literature concerning central nervous system spread and the molecular subtypes of such late tumors.

O câncer de mama é uma doença prevalente e sua incidência de metástase cerebral varia de 5 a $30 \%$, de acordo com a literatura. Apresentamos um caso de metástase cerebral tardia isolada em uma paciente do sexo feminino após um período de 16 anos do diagnóstico e tratamento. Durante esse período, não houve outra recorrência. Também é feita uma breve revisão da literatura sobre metástases de câncer de mama no sistema nervoso central e suas características moleculares.

\section{Introduction}

According to recent data, around 1,7 million new cases of breast cancer (BC) are diagnosed each year in women worldwide. It represents $25 \%$ of new cancer diagnoses in women. Only non-melanoma skin cancer has a greater prevalence. Between 5 and $30 \%$ of the patients with BC have seeding in the central nervous system (CNS). ${ }^{1-3}$ Therefore, the presence of patients with $\mathrm{BC}$ metastases in the neurosurgical centers is a common occurrence.

This report presents a patient who developed multiple cerebral metastases 16 years after the initial diagnosis, without any prior evidence of systemic disease. Such a delayed metastatic presentation in the CNS is unusual. ${ }^{3}$ We found

received

March 7, 2019

accepted

May 27, 2019
DOI https://doi.org/

10.1055/s-0039-1695016. ISSN 0103-5355. only one case with longer time between primary diagnosis and secondary brain metastasis (BM). ${ }^{4}$ Here, we also review the involvement of the CNS in breast cancer, as well as its molecular profile and prognosis.

\section{Case Report}

A 54-year-old female reported difficulty with manual dexterity in her right hand for 3 months. Neurological examination revealed no motor deficit in her arms. There was also postural instability and progressive worsening of gait, associated with headache and vomiting. She had cerebellar ataxia and dysmetria of the right upper limb. Brain magnetic resonance imaging (MRI) showed multiple supra and infratentorial expansive

Copyright @ 2019 by Thieme Revinter
Publicações Ltda, Rio de Janeiro, Brazil

License terms

c) $(\oplus) \$$ 
lesions (-Fig. 1). The largest one was located in the right cerebellar hemisphere. Oncological screening excluded any other site of primary tumor or metastatic lesions.

The patient had been diagnosed with breast cancer in May 2001. A radical mastectomy was performed then, with axillary node clearance. In addition, she received radiotherapy and adjuvant chemotherapy. The histological study evidenced ductal adenocarcinoma, positive for estrogen receptors (ERs), progesterone receptors (PRs), and human epidermal growth factor receptor type 2 (HER 2)- a "triple positive". In the following year, she underwent prophylactic bilateral oophorectomy and was treated for 5 years with tamoxifen.

The neurosurgical and oncological team opted for immediate operative resection of the largest infratentorial lesion due to risk of hydrocephalus. Four days after the first MRI, the patient underwent cerebellar tumor resection in May 2017192 months after the first diagnosis-with total resection of the lesion, and she recovered postoperatively without complications (-Figure 2). She had significant improvement of
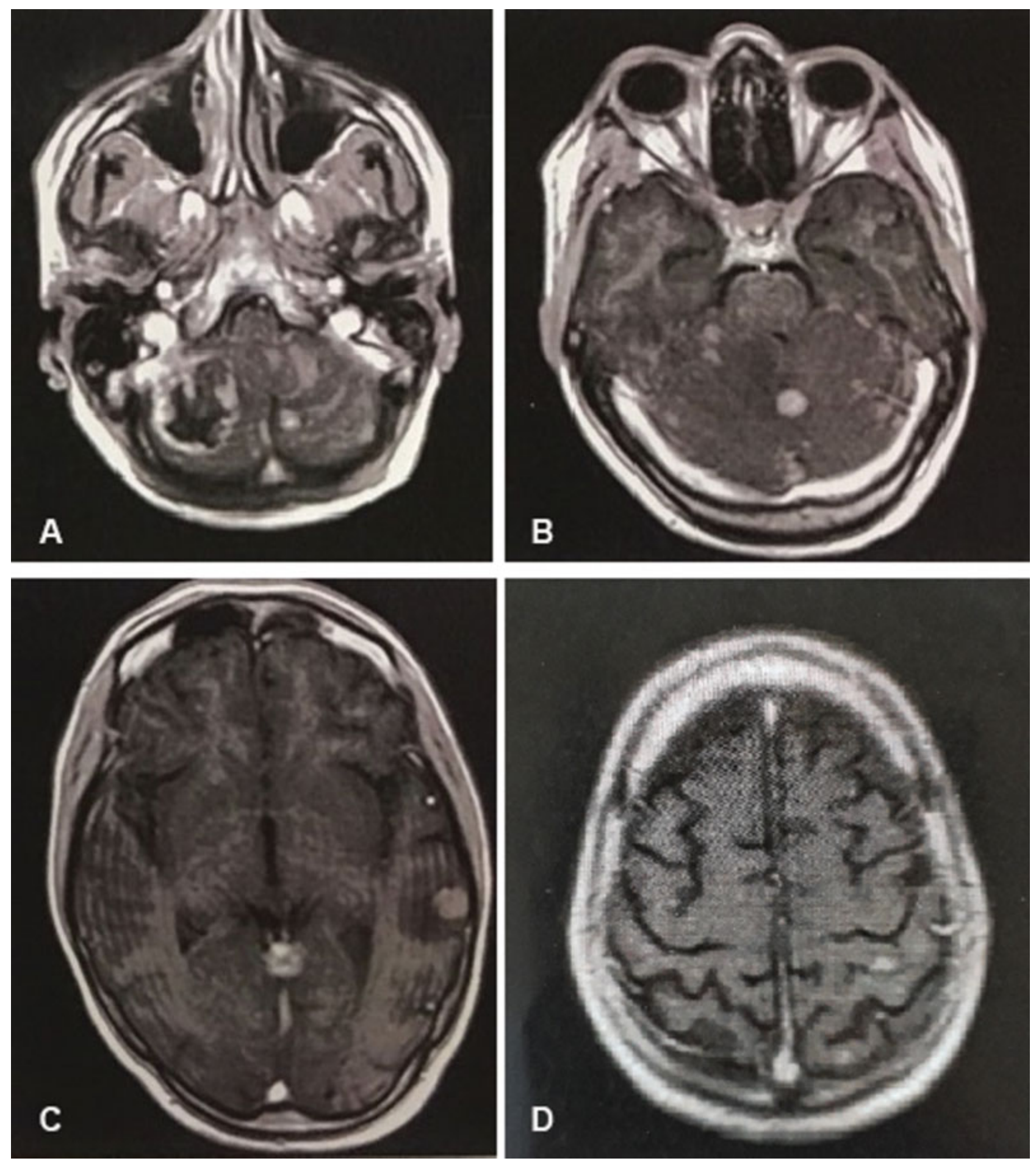

Fig. 1 Symptomatic cerebellar metastasis (A) Multiple metastases, infra and supratentorial (B, C, and D). 


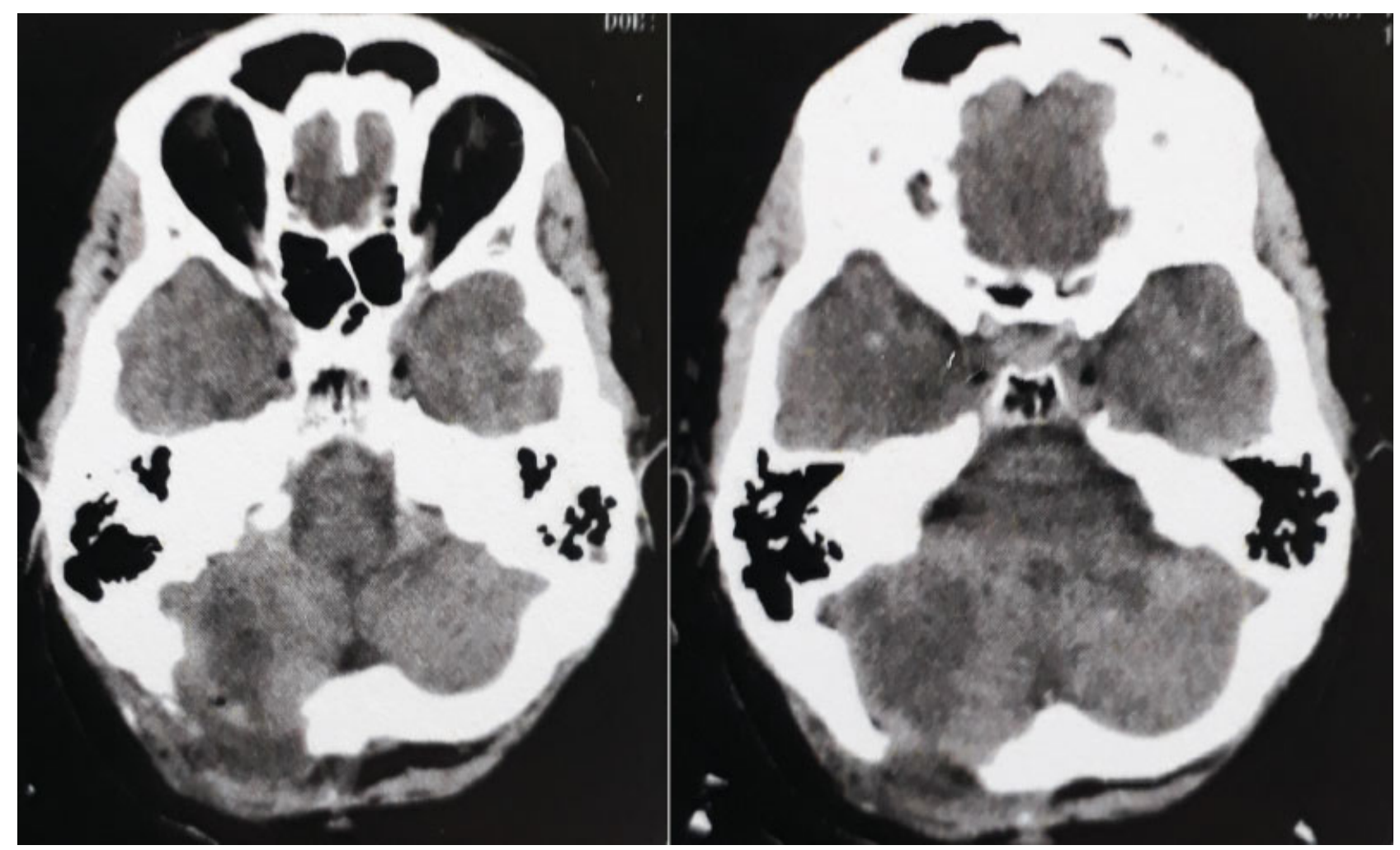

Fig. 2 Postoperative computed tomography.

symptoms and recovered capacity for all daily activities. Immunohistochemistry confirmed breast metastasis, with $10 \%$ of the neoplastic cells being progesterone receptor (PR)positive and Ki 67-positive.

Oncological treatment followed with adjuvant radiotherapy and chemotherapy. No more neurosurgical intervention was necessary in the follow-up of 12 months. An MRI and a positron emission tomography (PET)-scan exam 1 year later showed satisfactory control of brain lesions and absence of others metastases (-Figure $\mathbf{3}$ and $\mathbf{4}$ ).

\section{Discussion}

In Brazil, 57,960 new cases of BC were diagnosed in 2016, and 14,000 deaths were attributable to this disease. ${ }^{5}$ It is the second most prevalent type of tumor to cause metastasis to the CNS, following lung implants. Recent numbers in the literature indicate that up to $30 \%$ of metastatic presence in the nervous system in autopsy analysis. ${ }^{3}$ Modern methods of imaging, like MRI, and the longer survival time of these patients have contributed to a greater prevalence in recent years.

In a recent review, the mean age of patients at diagnosis of the brain metastases was 48.8 years. Multiple metastases are present in $54 \%$ of the cases, with cerebellum and frontal lobe being the most frequent locations. In addition, the mean time between diagnosis of the underlying disease and the BM was 32 months. $^{6}$

In a cohort study, the 5-year follow-up of $802 \mathrm{BC}$ patients showed an incidence of $5 \%$ (42) of BM. ${ }^{1}$ Another study that followed more than 9,000 patients showed incidence of 3.3\% in 5 years and $5.2 \%$ in $10 .^{2}$

We searched for late metastasis in the literature. A comprehensive review with more than 14,000 patients showed the diagnosis of BM varying from 1 to 97 months after detection of the primary disease. ${ }^{6}$ In another review study, only $0.1 \%$ of cases present a CNS involvement as $1^{\text {st }}$ site after 10 years. $^{2}$ The longest reported case of late CNS metastases from $B C$ was at 193 months of the $1^{\text {st }}$ diagnosis. ${ }^{4}$

Analyzing biomarkers characteristics, Altundag et al described a relation of estrogen receptor (ER)-negative and HER2 positive tumors to patients presenting CNS spread. Although, among the 420 patients evaluated by the group a better prognosis was observed in the ones with ER-positive tumors. Patients younger than 50 years old have longer survival too. Trastuzumab, a monoclonal antibody therapy used for HER-2 positive patients, is related to better disease control. Other risk factors were positive sentinel lymph node, younger patients, and tumor grade. Of note, these factors are described to increase not only CNS spread, but also systemic. ${ }^{3}$

Moreover, Shen et al showed HER-2 expression as an independent predictor of better survival in patients treated with craniotomy for BM stemming from BC. In this same analysis, patients with positive ER and PR, presented longer survival after cerebral metastatic diagnosis compared to one or two negative receptors. ${ }^{7}$

Lin et al discussed the epidemiology and prognosis of HER-2 status in BM. They supported the biomarker as a risk factor for CNS spread, because of its inherent behavior and also because of longer survival of patients treated with 

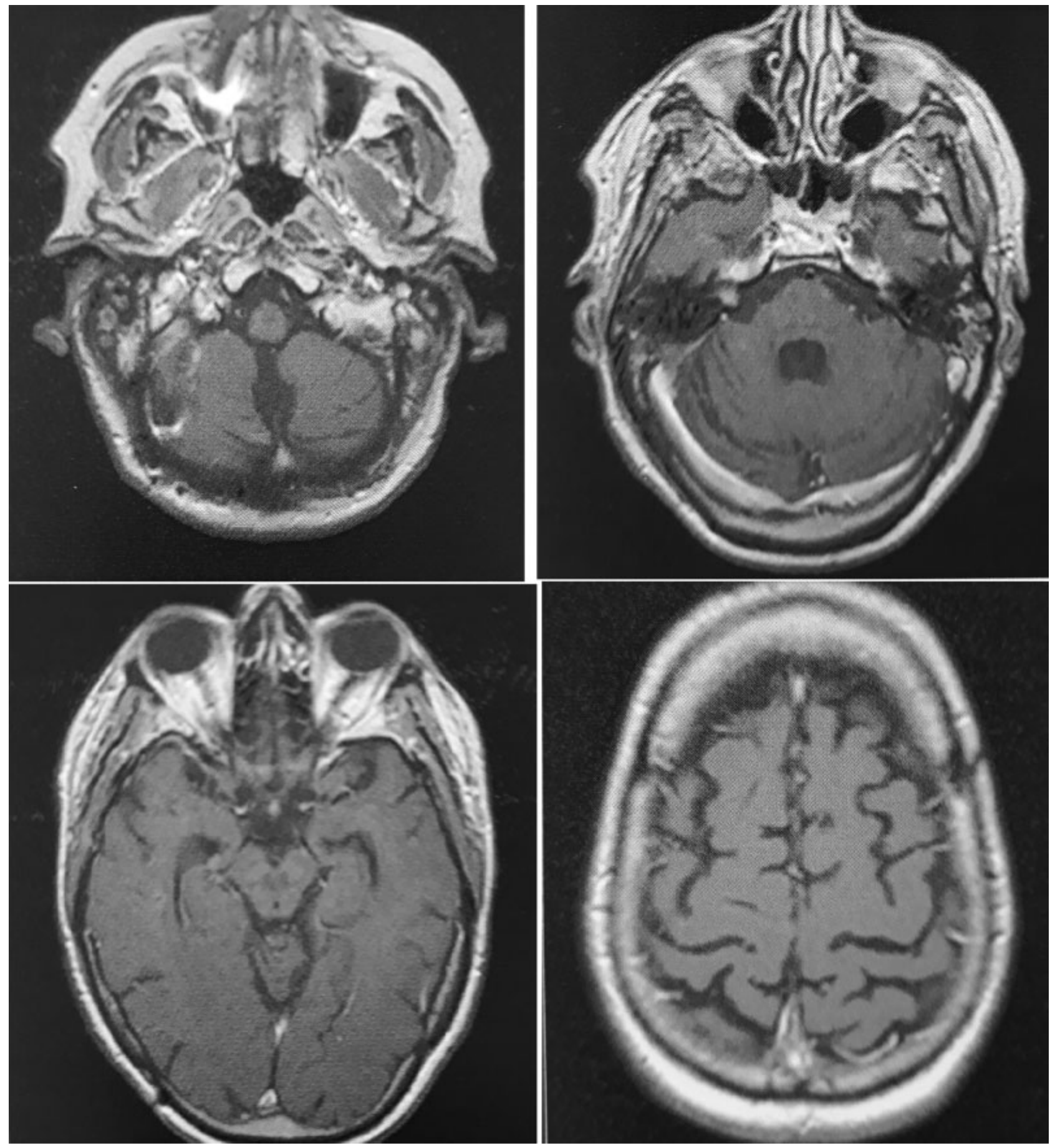

Fig. 3 Control magnetic resonance imaging after surgery, chemotherapy and adjuvant radiotherapy.

monoclonal therapy. ${ }^{8}$ Similar data was found by others authors. ${ }^{9,10}$

Overall, the prognosis of these patients is associated with the presence of implantation in different organs, size and degree of the primary lesion in breast, negative hormone receptors, clinical performance at the time of diagnosis, and progression-free survival. Karnofsky performance status was also important for overall survival. ${ }^{11}$ The mean life expectancy after the identification of BM is 17 months. ${ }^{6} \mathrm{~A}$ study that exclusively examined patients who underwent craniot- omy for treatment of the BM presented a mean survival of 1.3 years. ${ }^{12}$

These patients benefit from multimodal approaches, with adjuvant radiotherapy and chemotherapy. In fact, more than half of the patients undergo whole brain radiation, and up to $20 \%$ have an indication of stereotactic treatment. ${ }^{6}$

The improvement of survival in patients with positive HER-2 BC, and the advances in diagnostic option, allowed for such a delayed CNS BM. 


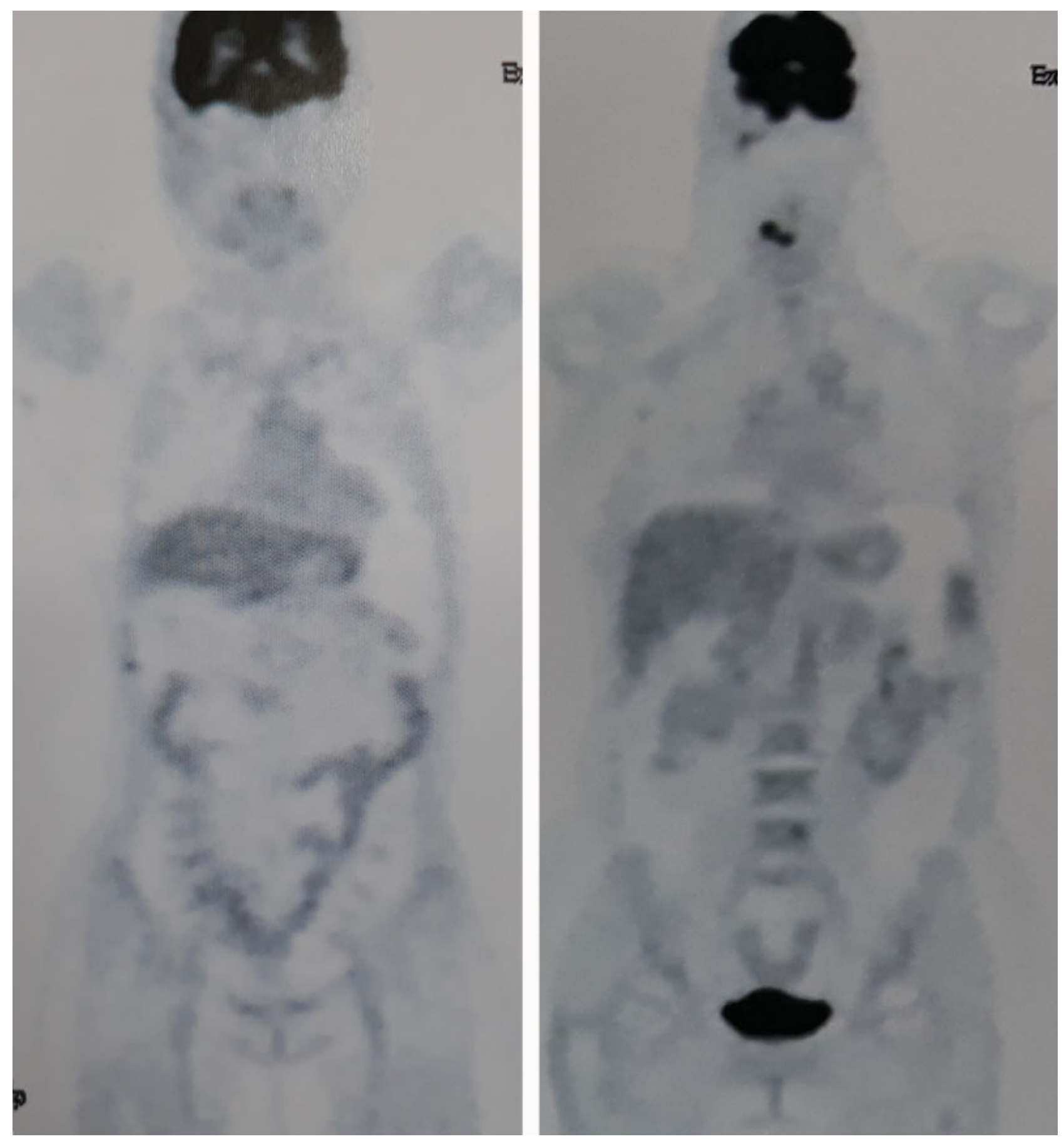

Fig. 4 Positron Emission Tomography-computed tomography confirms patient with no other implant.

\section{Conflicts of Interest}

The authors have no conflicts of interest to declare.

\section{References}

1 Schouten LJ, Rutten J, Huveneers HAM, Twijnstra A. Incidence of brain metastases in a cohort of patients with carcinoma of the breast, colon, kidney, and lung and melanoma. Cancer 2002;94 (10):2698-2705

2 Pestalozzi BC, Zahrieh D, Price KN, et al; International Breast Cancer Study Group (IBCSG). Identifying breast cancer patients at risk for Central Nervous System (CNS) metastases in trials of the International Breast Cancer Study Group (IBCSG). Ann Oncol 2006;17(06):935-944

3 Altundag K, Bondy ML, Mirza NQ et al. Clinicopathologic characteristics and prognostic factors in 420 metastatic breast cancer patients with central nervous system metastasis. Cancer 2007; 110(12):2640-2647

4 Yamada SM, Tomita Y, Shibui S, Kurokawa T, Baba Y. A Case of Breast Cancer Brain Metastasis with a 16-Year Time Interval without Evidence of Cancer Recurrence. J Breast Cancer 2017;20(02):212-216

5 http://www.inca.gov.br - Instituto Nacional de Câncer, Brasil 
6 Rostami R, Mittal S, Rostami P, Tavassoli F, Jabbari B. Brain metastasis in breast cancer: a comprehensive literature review. J Neurooncol 2016;127(03):407-414

7 Shen Q Sahin AA, Hess KR, et al. Breast cancer with brain metastases: clinicopathologic features, survival, and paired biomarker analysis. Oncologist 2015;20(05):466-473

8 Lin NU, Winer EP. Brain metastases: the HER2 paradigm. Clin Cancer Res 2007;13(06):1648-1655

9 Hung M-H, Liu C-Y, Shiau C-Y, et al. Effect of age and biological subtype on the risk and timing of brain metastasis in breast cancer patients. PLoS One 2014;9(02):e89389
10 Dayan A, Koca D, Akman T, Oztop I, Ellidokuz H, Yilmaz U. The factors that have an impact on the development of brain metastasis in the patients with breast cancer. J Cancer Res Ther 2012;8 (04):542-548

11 Ogawa K, Yoshii Y, Nishimaki T, et al. Treatment and prognosis of brain metastases from breast cancer. J Neurooncol 2008;86(02): 231-238

12 Leone JP, Lee AV, Brufsky AM. Prognostic factors and survival of patients with brain metastasis from breast cancer who underwent craniotomy. Cancer Med 2015;4(07):989-994 